\title{
Experimental Investigation of a Diesel Engine Powered with Fuel Microemulsion
}

\author{
Krzysztof Górski
}

1 Faculty of Mechanical Engineering, Kazimierz Pulaski University of Technology and Humanities in Radom, ul. Chrobrego 45, 26-200 Radom, Poland

e-mail: krzysztof.gorski@uthrad.pl

\begin{abstract}
The paper presents the research results of the AVL diesel engine powered with microemulsion fuels. In particular the emission of soot particles from the engine operated under stationary conditions was investigated. The necessary tests were carried out for two microemulsions containing 3.5 and $7 \%$ by volume of distilled water dispersed in diesel fuel with necessary surfactants/cosurfactants, i.e. Crillet-6/Span-20. Both tested microemulsions contained similar water micelles size distribution with average dimension of $18 \mathrm{~nm}$. The results of the investigation confirmed that the combustion of tested water - fuel microemulsion in the AVL research engine reduces the emission of soot particles even by $50 \%$ in comparison with the diesel fuel.
\end{abstract}

Keywords: diesel engine; soot emission; fuel microemulsions, alternative fuel.

\section{INTRODUCTION}

The combustion of fossil fuels is the largest contributor to the climate change, representing about $57 \%$ of the total greenhouse gases [5] and it is largely produced from the transportation and industrial emissions. These sources of toxic gases and particles are harmful to the global ecology and the human health [14]. In order to protect the human life and environment, the local and global bodies are imposing strict regulations on the emission standard of vehicles along with the other pollutant emission sources. In particular, the significant reduction of Particulate Matter (PM) emission has been recommended from $0.14 \mathrm{~g} / \mathrm{km}$ (EURO 1, January 1992) to $0.005 \mathrm{~g} / \mathrm{km}$ (EURO 6 , September 2014) for the passenger diesel powered cars. According to the literature data, water as a fuel component can support this target [15]. However, to meet the afore-mentioned requirement, the particulate filters have been fitted to the vehicles powered with diesel engines. It should be pointed out that nowadays, similar filters are also necessary for the gasoline direct injection engines. The development in the fuel technology also supports the challenge related with the reduction of harmful gases emission into the environment. Therefore, the water-diesel (W/D) emulsion is found to be one of the best alternative fuels which reduces the emission of PM without any modification of the engine $[8,13]$. There is a special occurrence in W/D ignition, called the micro-explosion phenomena [16] that intrigues researchers worldwide, as it is non-existent in normal diesel combustion. It is a secondary atomization of the primary spray as a result of the rapid evaporation process of water that is initially contained in the oil drop, making the combustion more efficient $[4,7]$. The vaporisation of water present in the emulsified fuel lowers the peak temperature of the combustion and thus reduces particles as well as NOx formation. Thus, the pollutant emission is greatly reduced for the emulsified diesel with compared to the pure diesel. It should be also pointed that according to the available research, the emulsified fuel combustion generates less pollutants without sacrificing the engine efficiency [19]. 
It should be noted that the majority of studies show a remarkable reduction in PM when W/D was combusted. Ithnin et al. [12] tested the W/D fuel emulsion and found that PM was reduced by $45 \%$ compared with the standard diesel fuel. Other researchers showed that the soot particles emission was reduced even by $89 \%$ for the engine powered with the microemulsion fuel [18]. Hassanuddin et al. [9] investigated the durability of a diesel engine that is running on emulsion fuels with $10 \%$ and $20 \%(\mathrm{v} / \mathrm{v})$ water content (E10, E20). The engine was running for $200 \mathrm{~h}$ and the result reported that emulsion fuels produced less carbon deposit with $65 \%$ and $52 \%$ reduction for E10 and E20, respectively.

The reduction of PM when using W/D is perhaps due to the better mixing and enhanced atomization caused by the micro-explosion phenomena [6]. Moreover, the addition of water in the emulsion augments the concentration of the (hydroxyl) $\mathrm{OH}$ radicals, which leads to the oxidation of soot precursors [20]. Ochoterena et al. [18], concluded that the causes of the reduction of the PM emissions are lower flame temperature, rapid evaporation of water, decreasing of pyrolysis reaction and the enhanced oxidation of soot precursor due to the addition of $\mathrm{OH}$ radicals.

Almost all the researchers found empirically that the emission of soot particles decreases in the case of the emulsified fuel compared with the diesel fuel and this reduction is much greater for higher concentration of water [2, 21]. Nadeem et al. [17] investigated a 4-cylinder diesel engine using neat diesel and water emulsified diesel fuel containing 5, 10 and $15 \%$ water. They reported that the reduction of the PM emission was approximately $68 \%$ in the case of W/D15 compared with the standard diesel fuel. Ithnin et al. [12] tested 5\% water emulsified diesel fuel in a single cylinder diesel engine and observed a reduction in PM by $16.3 \%$ than for standard diesel. Badrana et al. [3] also confirmed lower PM emission from the diesel engine powered with emulsified fuel compared to the standard diesel fuel. In details, they obtained a reduction of PM by $95 \%$ when the engine was fuelled with $30 \%$ water emulsified fuel.

Ithnin et al. [12] confirmed the lower PM emission with emulsified diesel fuel compared with standard diesel fuel. It was attributed to the better combustion due to the micro-explosion phenomenon. They also concluded that the lower PM emission was caused by a reduced flame temperature. Moreover, less pyrolysis reaction and extended oxidation of soot precursors occurred due to higher concentration of $\mathrm{OH}$ radicals in W/D impact on the lowering of PM.

Despite its positive influence on the environment, emulsified diesel fuel has a major weakness which is low stability. It means that such fuel emulsions easily separate. In order to prevent the phase separation of oil and water, necessary surfactants/cosurfactants are utilized $[8,10]$. These selected chemicals allow creating stable fuel microemulsions. It should be pointed that microemulsions are transparent while emulsions are milky due to different micelles size. In the case of microemulsion, the average size of dispersed water droplets is lower than the wavelength of visible light (from about 380 to 740 nanometers). The diameter of micelles dispersed in the emulsion fuel is usually higher than $1 \mu \mathrm{m}$. For this reason, these large droplets reflect light that makes the emulsion appear white.

The emulsifier chemistry and emulsions are well-known subjects of numerous studies. In contrast, the knowledge on microemulsions is not so wide. In particular, there is a lack of the research focusing on the particles emission from modern Common Rail diesel engine fuelled with microemulsion. Therefore, a detailed analysis of the $\mathrm{PM}$ emission from the AVL research engine was conducted using two fuel microemulsions containing 3.5 and $7(\%, \mathrm{v} / \mathrm{v})$ of distilled water and compared with diesel fuel.

\section{MATERIALS AND METHODS}

In this research, the laboratory equipment shown in Figure 1 has been used. The main part of this test stand is the AVL 5402 series Common Rail diesel research engine. It should be pointed that the engine was not equipped with a diesel particulate filter (DPF). The stand was built by the AVL Co. for the Kazimierz Pulaski University of Technology and Humanities in Radom (UTH Radom).

The AVL 5402 series research engine is a well-known unit designed for professional scientific tests. The engine cylinder was equipped with 4 valves and direct fuel injection system made by $\mathrm{BOSCH} \mathrm{Co}$. The other fundamental specifications of the engine are shown in Table 1. The test stand was equipped with the AVL Micro Soot Sensor 


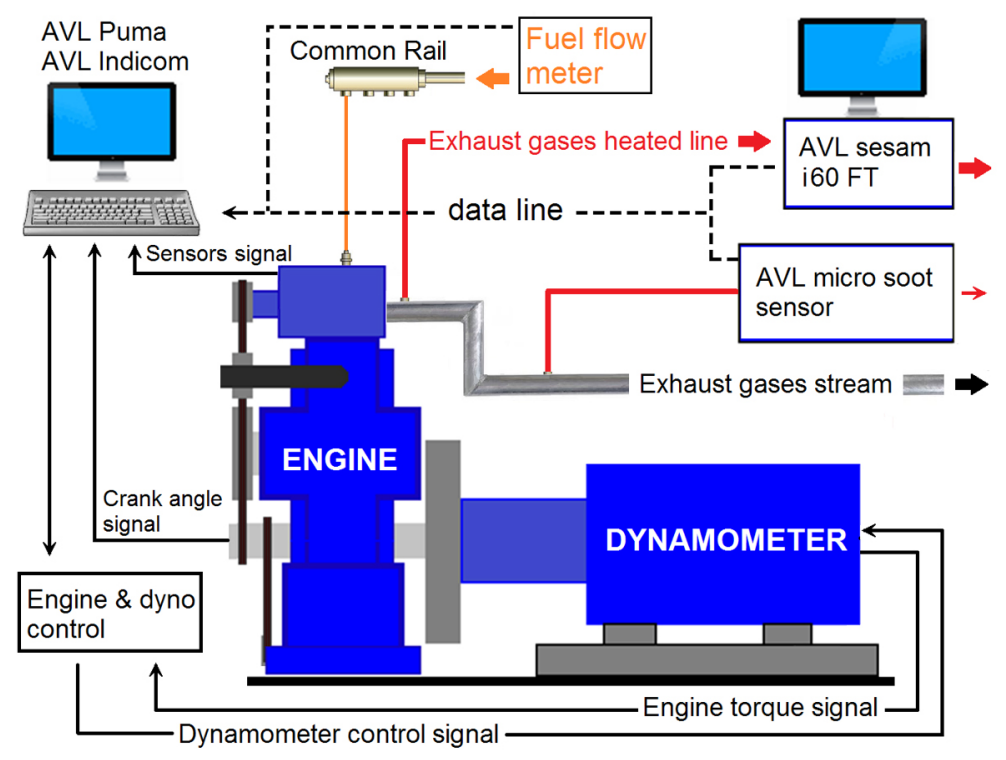

Fig. 1. Schematic diagram of the test stand equipped with the AVL 5402 research engine

(MSS) designed for the detection of soot particles based on the photoacoustic effect (Fig. 2).

In this method the exhaust gas is periodically radiated with the $808 \mathrm{~nm}$ laser light. The particulates of soot interact with the light and release absorbed energy as heat and pressure rise. The process occurs with certain frequency of the light absorption by PM. The periodical heating and cooling of these particles generates the pressure pulsation detected by a microphone. The obtained signal is proportional to the soot concentration in the exhaust gases stream. The fundamental technical data of the AVL MSS are listed in Table 2.

The necessary measurements of the soot concentrations began when the stationary condition of the engine work has been achieved. For this reason, the engine coolant and oil temperature was also controlled. Once these parameters became steady, the concentrations of the soot

Table 1. Technical data of the AVL 5402 research engine

\begin{tabular}{|l|l|}
\hline \multicolumn{1}{|c|}{ Parameter } & \multicolumn{1}{c|}{ Value } \\
\hline Engine type & 4-stroke, single cylinder \\
\hline Cooling system & liquid \\
\hline Fuel injection type & Common Rail, BOSCH CP4.1 \\
\hline $\begin{array}{l}\text { Maximum injection } \\
\text { pressure }\end{array}$ & $180 \mathrm{MPa}$ \\
\hline $\begin{array}{l}\text { Maximum power without } \\
\text { turbocharging }\end{array}$ & $6.25 \mathrm{~kW}$ at 4200 rpm \\
\hline Compression ratio & $17,5: 1$ \\
\hline Engine controller & $\mathrm{AVL}-\mathrm{RPEMS}+\mathrm{ETK} 7 \mathrm{BOSCH}$ \\
\hline Displacement & $510.7 \mathrm{~cm}^{3}$ \\
\hline Valves per cylinder & 2 inlet, 2 exhaust \\
\hline
\end{tabular}

particles expressed as $m g \cdot m^{-3}$ were measured by the AVL MSS. Additionally, the exhaust flow at a given power was recorded. In this way the specific soot emission (SSC) expressed as $g \cdot k W h^{-1}$ was calculated for all tested fuels.

As mentioned above, the engine tested in this research uses the $\mathrm{CR}$ injection system controlled by programmable Engine Control Unit (ECU). The parameters of the injection timing used in this research were the same for all tested fuels. The necessary details are listed in Table 3 .

It should be pointed that during research, the turbocharging system as well as exhaust gases recirculation (EGR) were disabled. In this way, the number of independent variables was reduced. The main goal of the empirical research was to find out an impact of the water content dispersed in the diesel fuel on PM emission. For this reason, a diesel fuel and two fuel microemulsions containing 3.5 and $7(\%, v / v)$ of distilled water were tested in this study. These fuels were designated as follows: DF0, DF3.5 and DF7, respectively.

Water was dispersed in a diesel fuel in the form of micelle structures using surfactants/cosurfactants i.e. Crillet-6 (CAS no.: 66794-58-9)

Table 2. Technical data of the AVL Micro Soot Sensor

\begin{tabular}{|l|c|}
\hline \multicolumn{1}{|c|}{ Parameter } & Value \\
\hline Measuring range & $0.001-50 \mathrm{mg} / \mathrm{m}^{3}$ \\
\hline Display resolution & $0.01 \mathrm{mg} / \mathrm{m}^{3}$ \\
\hline Detection limit & $1 \mu \mathrm{m} / \mathrm{m}^{3}$ \\
\hline Sample flow & $4 \mathrm{~L} / \mathrm{min}$ \\
\hline Data rate & $10 \mathrm{~Hz}$ \\
\hline
\end{tabular}




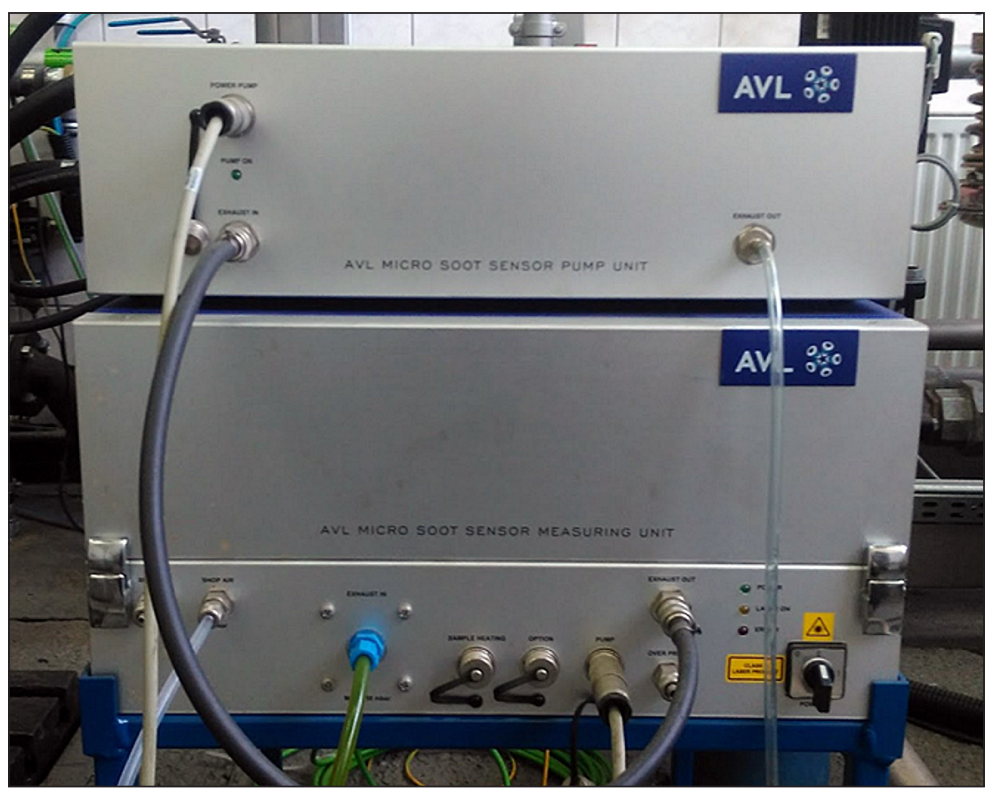

Fig. 2. View of the AVL Micro Soot Sensor installed at the engine test stand at UTH Radom

Table 3. Parameters of injection timing, i.e. the pilot and the main fuel dose for all tested conditions of engine work

\begin{tabular}{|c|c|c|c|c|}
\hline Speed, rpm & BMEP $^{*}$, bar & Power, kW & $\begin{array}{l}\text { The pilot injection timing, } \\
{ }^{\circ} \mathrm{CA} \text { before TDC }\end{array}$ & $\begin{array}{c}\text { The main injection timing, } \\
{ }^{\circ} \mathrm{CA} \text { before TDC }\end{array}$ \\
\hline \multirow{3}{*}{1200} & 1.7 & 0.9 & \multirow{3}{*}{13} & \multirow{3}{*}{3.8} \\
\hline & 3.4 & 1.7 & & \\
\hline & 5.1 & 2.6 & & \\
\hline \multirow{3}{*}{2200} & 1.7 & 1.6 & \multirow{3}{*}{17.7} & \multirow{3}{*}{9.9} \\
\hline & 3.4 & 3.2 & & \\
\hline & 5.1 & 4.8 & & \\
\hline \multirow{3}{*}{3200} & 1.7 & 2.3 & \multirow{3}{*}{25.4} & \multirow{3}{*}{11.3} \\
\hline & 3.4 & 4.7 & & \\
\hline & 5.1 & 7.1 & & \\
\hline
\end{tabular}

and Span-20 (CAS no.: 1338-39-2). The content of both these chemicals in the tested fuels was $6 \%$ by mass. Such content was necessary for dispersing water in the top volume of $7 \%$. The afore-mentioned surfactants/cosurfactants were blended with the diesel fuel. Then, small portions of distilled water were added until a target volume of 3.5 and $7 \%$ was achieved. The technology process was carried out at a temperature of $40{ }^{\circ} \mathrm{C}$. The obtained microemulsions were transparent and stable during long term storage, i.e. 3 months at a room temperature. The water micelles size distribution of the tested microemulsions was confirmed in the research carried out with the Zetasizer Nano analyzer. The Zetasizer instrument is a professional tool used to measure the size and size distribution of particles using light scattering method. In this research, the micelles size distribution was tested 3 times for both microemulsion. The results of these tests confirmed that both tested microemulsions had similar distribution of micelles size with average value of $18 \mathrm{~nm}$. The selected physicochemical properties of all tested fuels (DF0, DF5, DF10) are listed in Table 4.

The kinematic viscosity and density of all tested fuels were measured according to the requirements of EN ISO 3104 and EN ISO 3838 standards, respectively. The temperature-dependent parameter i.e. cold filter plugging point was measured in agreement with EN 116:2015 standards. The copper strip corrosion test was performed according to the ASTM D-130 standard. Taking into account the data presented in Table 4 it can be stated that the low-temperature properties of both tested W/D were slightly lower compared with a diesel fuel. It was found that the viscosity of DF5 and DF10 increased significantly, 
Table 4. Selected physicochemical properties of tested fuels

\begin{tabular}{|l|c|c|c|c|}
\hline \multirow{2}{*}{ Property } & \multirow{2}{*}{ Unit } & \multicolumn{3}{c|}{ Value } \\
\cline { 3 - 5 } & & DF0 & DF5 & DF10 \\
\hline Density at $15^{\circ} \mathrm{C}$ & {$\left[\mathrm{kg} / \mathrm{m}^{3}\right]$} & 837 & 851 & 855 \\
\hline Water content by volume & {$[\%]$} & 0 & 3.5 & 7.0 \\
\hline Crillet-6/Span-20 content by mass & {$[\%]$} & 6.0 & 6.0 & 6.0 \\
\hline Kinematic viscosity at $40^{\circ} \mathrm{C}$ & {$\left[\mathrm{mm}^{2} / \mathrm{s}\right]$} & 2.82 & 3.45 & 3.96 \\
\hline Cold filter plugging point & {$\left[{ }^{\circ} \mathrm{C}\right]$} & -15 & -13 & -11 \\
\hline Flash point & {$\left[{ }^{\circ} \mathrm{C}\right]$} & 66 & 80 & 106 \\
\hline Copper strip corrosion & {$[-]$} & $1 \mathrm{a}$ & $1 \mathrm{~b}$ & $1 \mathrm{~b}$ \\
\hline
\end{tabular}

compared with the standard diesel fuel. However, it should be pointed that the values of W/D kinematic viscosity still meet the requirements described in the EN590 standard. Empirical investigation confirmed that a water dispersed in diesel fuel increases a flash point value. For this reason W/D are safer in transportation and more practical in special application e.g. combat vehicles.

\section{RESULTS AND DISCUSSION}

Figure 3 exhibits the specific soot concentration (SSC) obtained for DF0 and both tested W/D microemulsions containing 3.5 and $7.0 \%$ of $\mathrm{H} 2 \mathrm{O}$ $(\mathrm{v} / \mathrm{v})$ under three different loads of engine work, i.e. $\mathrm{BMEP}=1.7,3.4$ and $5.1 \mathrm{bar}$ at $1200 \mathrm{rpm}$ of the crankshaft. Figure 3 clearly shows that the formation of soot is reduced for both tested microemulsions compared with DF0. However, the highest reduction of soot was obtained for the engine powered with DF3.5. For this fuel the soot emission was reduced in range $28-45 \%$ in comparison with DF0. It should be pointed that the microemulsion containing $7 \%$ of water is not so effective. In this case, the reduction of soot reaches $10-12 \%$. Similar results (Fig. 4) were obtained for the engine operated with middle speed $2200 \mathrm{rpm}$ of the crankshaft. As it can be seen from this figure, the soot emission is comparable to the results presented above. It can be observed that soot emission is always lesser with W/D even by $60 \%$ for DF3.5 at 1.7 BMEP, compared with the diesel fuel.

Once again, it was found that the highest water addition to diesel fuel is not so effective in soot reduction. It confirms that the water content in the W/D microemulsion should be optimized for specific requirements and fuel injection settings of the engine. In this research, the highest soot emission was detected at $3200 \mathrm{rpm}$ and 5.1 BMEP (Fig. 5). In this case, the top emission from the AVL engine fuelled with DF0 reaches $75 \mathrm{mg} / \mathrm{kWh}$.

One can note from Figure 5 that a reduction of soot for emulsified diesel containing 3.5\% of water at full load condition is about $32 \%$ lower in comparison with the diesel fuel. The figure

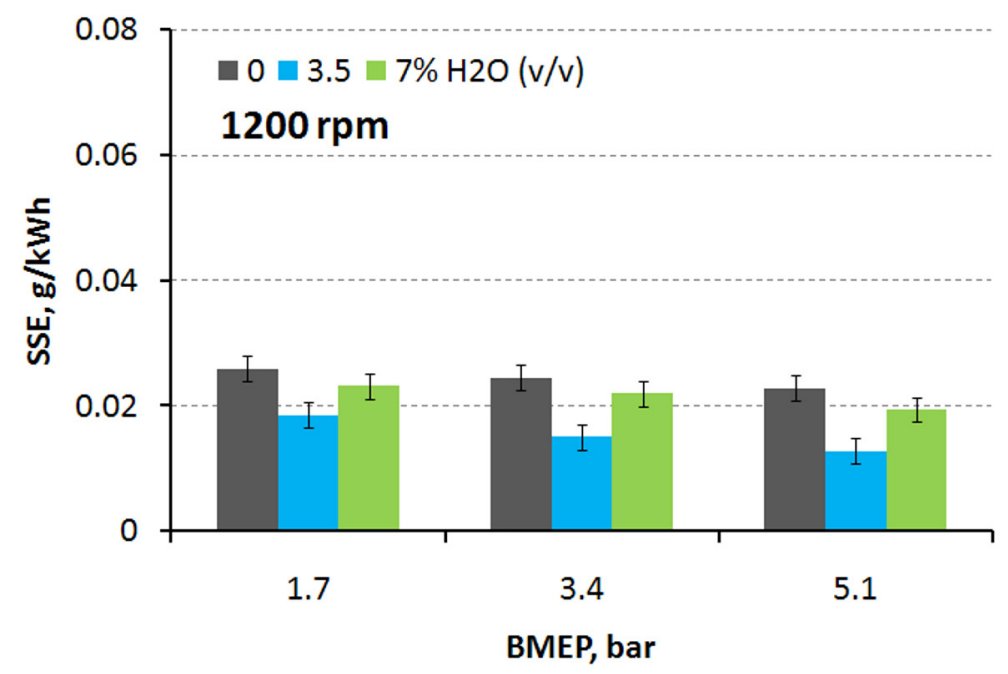

Fig. 3. The specific soot emission (SSE) for the AVL engine operated at $1200 \mathrm{rpm}$ 


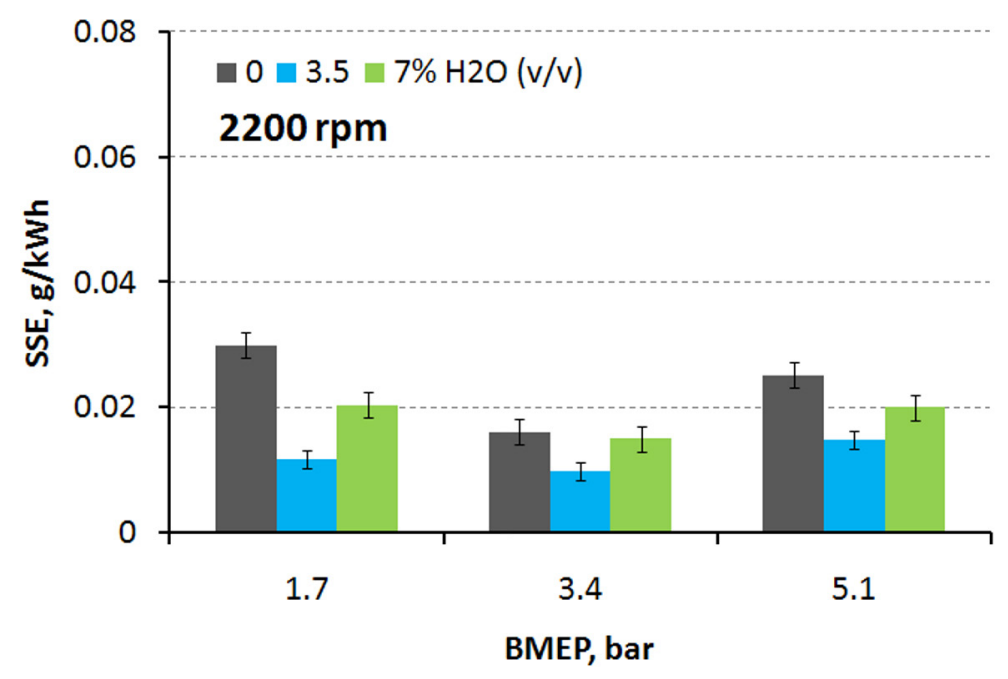

Fig. 4. The specific soot emission (SSE) for the AVL engine operated at $2200 \mathrm{rpm}$

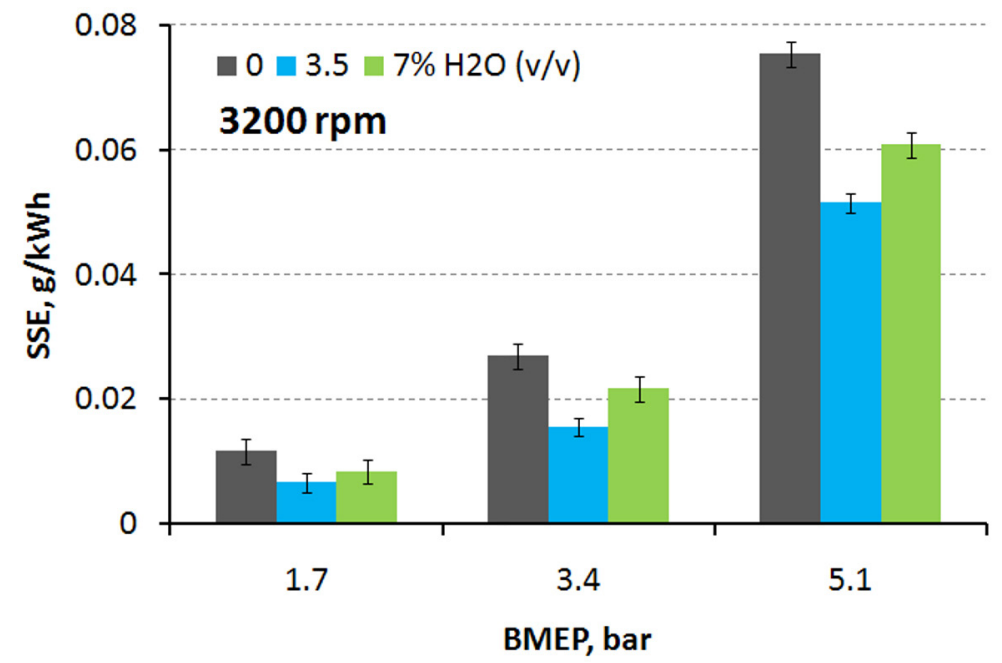

Fig. 5. The specific soot emission (SSE) for the AVL engine operated at $3200 \mathrm{rpm}$

also indicates the soot emission increases with the engine load for all tested fuels. This may be due to greater fuel feeding at higher engine load which produces proportional higher amount of soot. Their particulates are formed during the incomplete combustion of diesel fuel in regime of higher temperature. After fuel injection, the hydrocarbon droplets vaporize in hot environment of combustion chamber. In such conditions solid particles containing carbon atoms are formed. The main precursors of soot are poly-cyclic aromatic hydrocarbons (PAH). Once formed, the soot nuclei grows in the coagulation process. For this reason number of soot particles tends to be lower. However, a size and mass of these particles is still very small. It changes in the process of surface growth. The carbon atoms from the gas phase interact with the soot particle surface leading to a growth of its size and mass. It can be stated that the formation of these soot aggregates is reduced by the water molecules. It is possible that at the beginning of combustion, the heat breaks up the water micelles and in this way the atomization of fuel droplets is supported. Better fuel atomization always increases the efficiency of the combustion process with adequately lower emission of harmful gases components. Some reports suggest that in hot environment of combustion chamber a water molecule splits into the hydrogen and oxygen atoms. Then these chemical active atoms interact with the hydrocarbon molecules supporting combustion. However, such mechanism is a minor one because the temperature in the combustion chamber is too low. On the other hand, it is known that the high-temperature water (HTW) is significantly more reactive than 
liquid water under normal conditions. It should be noted that HTW is defined as liquid water above $200{ }^{\circ} \mathrm{C}$ under high pressure. The literature data confirms that HTW can support ionic, polar nonionic and free-radical reactions [1]. If so, a water injected into the combustion chamber can interact with hydrocarbons including PAHs, and in this way the formation of soot is reduced. It should be pointed that computational study suggests that water can promote the formation of nitro-PAHs [22]. However, the impact of these chemicals on soot formation is not fully known.

\section{CONCLUSIONS}

In this paper, two microemulsions containing 3.5 and $7 \%(\mathrm{v} / \mathrm{v})$ of distillate water dispersed in diesel fuel were tested in the AVL research diesel engine for the first time. The results confirmed that the emission of soot particles can be significantly reduced even by $50 \%$ compared with diesel fuel. Such result was obtained when only $3.5 \%(\mathrm{v} / \mathrm{v})$ of distillate water was dispersed in a diesel fuel. It was found that the higher content of water dispersed in the diesel fuel is not recommended due the efficiency of soot reduction decrease. The water content in the diesel fuel should be optimized for specific requirements. On the basis of the results it should be pointed that even a small addition of water can be good enough in the reduction of soot. The findings of this work carried out for microemulsion suggest, that both fuels i.e. emulsions as well as microemulsions are equally efficient in the reduction of the soot particles. However, it should be pointed out that microemulsions are significantly more stable in comparison with the emulsion fuels. For this reason, the microemulsion fuels can be recommended for further research as an alternative and environmental friendly fuel for the modern diesel engines.

\section{REFERENCES}

1. Akiya N. and Savage P.E. Roles of Water for Chemical Reactions in High-Temperature Water. Chem. Rev. 102(8), 2002, 2725-2750

2. Armas O., Ballesteros R., Martos F.J. and Agudelo J.R. Characterization of light duty diesel engine pollutant emissions using water-emulsified fuel. Fuel, 84(7-8), 2005, 1011-1018.

3. Badrana O., Emeish S., Abu-Zaid M.Z. and
Abu-Rahmeh T. Impact of emulsified water/diesel mixture on engine performance and environment. Int. J. of Thermal \& Environmental Engineering, 3(1), 2011, 1-7.

4. Ballester J.M., Fueyo N. and C. Dopazo, Combustion characteristics of heavy oil-water emulsions. Fuel, 75(6), 1996, 695-705.

5. Barker T, Bashmakov I, Bernstein L, Bogner J, Bosch P, Dave R et al. Technical Summary. In Climate change 2007: Mitigation. In Metz B, Davidson OR, Bosch PR, Dave R, Meyer LA, editors, Contribution of Working group III to the Fourth Assessment Report of the Intergovernmental Panel on Climate Change. Cambridge, UK and New York, NY, USA: Cambridge University Press. 2007.

6. Fu W.B., Hou L.Y., Wang L. and Hua Ma F. A unified model for the micro-explosion of emulsified droplets of oil and water. Fuel Processing Technology, 79(2), 2002, 107-119.

7. Ghojel J., Honnery D. and Al-Khaleefi K., Performance, emissions and heat release characteristics of direct injection diesel engine operating on diesel oil emulsion. Applied Thermal Engineering, 26(17-18), 2006, 2132-2141.

8. Hagos F.Y., Aziz A.R.A. and Tan I.M. Water-indiesel emulsion and its micro-explosion phenomenon-review. 3rd International Conference on Communication Software and Networks (ICCSN), 2011 IEEE.

9. Hasannuddin A., Wira J.Y., Sarah, S., Ahmad M.I., Aizam S.A., Aiman M.A.B., Watanabe S., Hirofumi N. and Azrin, M.A. Durability studies of single cylinder diesel engine running on emulsion fuel. Energy, 94, 2016, 557-568.

10. Hasannuddin A., Wira J. Y., Srithar R., Sarah S., Ahmad M. I., Aizam S. A., Aiman M.A.B., Zahari M., Watanabe S., Azrin M.A. and Mohdet S.S. Effect of emulsion fuel on engine emissions-A review. Clean Technologies and Environmental Policy, 18(1), 2016, 17-32.

11. Ithnin A.M., Noge H., Abd Kadir H. and Jazar Yahya W. An overview of utilizing water-in-diesel emulsion fuel in diesel engine and its potential research study. Journal of the Energy Institute, 87(4), 2014, 273-288.

12. Ithnin A.M., Ahmad M.A., Abu Bakar M.A., Rajoo S. and Yahya W.J. Combustion performance and emission analysis of diesel engine fuelled with water-in-diesel emulsion fuel made from low-grade diesel fuel. Energy Conversion and Management, 90, 2015, 375-382.

13. Lif A. and Holmberg K. Water-in-diesel emulsions and related systems. Advances in colloid and interface science, 123, 2006, 231-239.

14. Lin C.Y. and Chen L.W. Comparison of fuel properties and emission characteristics of 
two-and three-phase emulsions prepared by ultrasonically vibrating and mechanically homogenizing emulsification methods. Fuel, 87(10-11), 2008, 2154-2161.

15. Mondal P.K. and Mandal B.K. A comprehensive review on the feasibility of using water emulsified diesel as a CI engine fuel. Fuel, 237, 2019, 937-960.

16. Mura E., Josset Ch., Loubar K., Huchet G. And Bellettre J. Effect of Dispersed Water Droplet Size in Microexplosion Phenomenon Forwater in Oil Emulsion. Atomization and sprays, 20(9), 2010, 791-799.

17. Nadeem M., Rangkuti C., Anuar K., Hag M.R.U., Tan I.B. and Shah S.S. Diesel engine performance and emission evaluation using emulsified fuels stabilized by conventional and gemini surfactants. Fuel, 85(14-15), 2006, 2111-2119.

18. Ochoterena R., Lif A., Nyden M., Andersson S. and Denbratt I. Optical studies of spray development and combustion of water-in-diesel emulsion and microemulsion fuels. Fuel, 89(1), 2010, 122-132.

19. Singh N.K. Experimental investigations of diesel emulsions as fuel in small direct injection compression ignition engines. MIT International journal of mechanical engineering, 2(1), 2012, 39-44.

20. Sheng H.Z., Chen L. and Wu C.K. The droplet group micro-explosions in W/O diesel fuel emulsion sprays. SAE transactions, 1995, 1534-1542.

21. Yang W., An H., Chou S.K., Chua K.J., Mohan B., Sivasankarlingam V., Raman V. Maghbouli A. and Li J. Impact of emulsion fuel with nano-organic additives on the performance of diesel engine. Applied energy, 112, 2013, 1206-1212.

22. Zhang Qi., Gao R., Xu F., Zhou Qi., Jiang G., Wang T., Chen J., , Hu J., Jiang W., Wang W. Role of Water Molecule in the Gas-Phase Formation Process of Nitrated Polycyclic Aromatic Hydrocarbons in the Atmosphere: A Computational Study. Environ. Sci. Technol. 2014, 48, 9, 5051-5057 